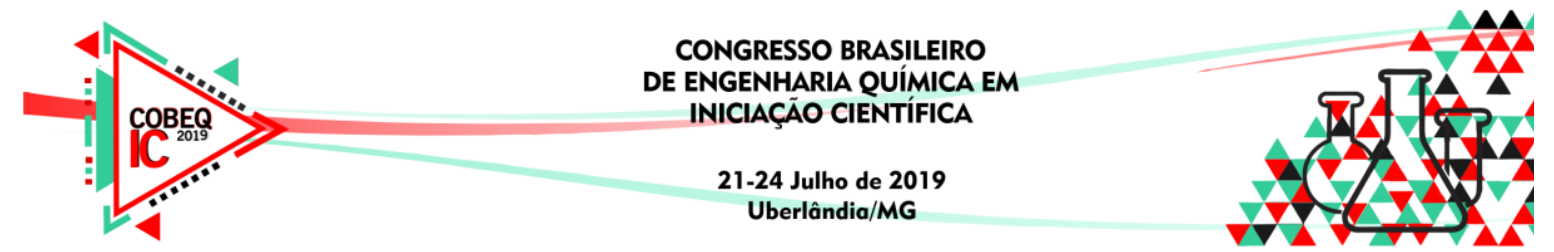

\title{
ESTUDO DA INFLUÊNCIA DE SAIS DE SÓDIO NA MASSA ESPECÍFICA E SÓLIDOS TOTAIS EM UMA SOLUÇÃO AQUOSA DE LIGNINA KRAFT
}

\author{
L. C. M. GOMES ${ }^{1}$, V. M. V. CRUZ ${ }^{1}$, G. PROENÇA ${ }^{1}$ e J. V. H. DANGELO ${ }^{1}$ \\ ${ }^{1}$ Universidade Estadual de Campinas, Faculdade de Engenharia Química/DESQ \\ E-mail para contato: luisacmgomes@gmail.com
}

\begin{abstract}
RESUMO - Na produção de celulose, o licor negro é obtido como subproduto da etapa de polpação. Ele é formado principalmente por água, lignina (proveniente da madeira) e sais de sódio $\left(\mathrm{Na}_{2} \mathrm{SO}_{4}\right.$ e $\mathrm{Na}_{2} \mathrm{CO}_{3}$ em maior quantidade). Esses últimos são gerados a partir do licor branco, solução utilizada para digerir a madeira. No processo Kraft, o mais utilizado mundialmente para polpação de celulose, o licor negro passa por uma unidade de recuperação. Atualmente tem-se investido em procedimentos para recuperar a lignina presente no licor. Para operar todos esses processos que envolvem a manipulação do licor com maior eficiência, é necessário conhecer suas propriedades físico-químicas. São essas propriedades que definem como o licor se comporta nas unidades industriais, sendo influenciadas pela composição química da solução. Assim, o licor foi reproduzido em laboratório a partir de concentrações controladas dessas três substâncias principais que o compõem e foram analisadas as influências que essas possuem sobre a massa específica e sólidos totais do licor.
\end{abstract}

\section{INTRODUÇÃO}

A madeira é constituída principalmente por celulose, hemicelulose e lignina. Enquanto a celulose forma as fibras da parede celular, os demais são os agentes ligantes entre essas fibras. A ruptura dessa estrutura da madeira ocorre em processos químicos como a polpação Kraft para a extração de celulose e, a partir desta, a produção de papel. Representando $70 \%$ da produção mundial (IEA ETSAP, 2015), este processo de polpação consiste no cozimento de cavacos de madeira em altas temperatura e pressão, com uma solução aquosa de hidróxido de sódio e sulfeto de sódio, denominada licor branco.

Durante a polpação é produzido como subproduto do processo o licor negro, solução aquosa que contém matéria orgânica (basicamente lignina) e inorgânica (sais minerais da madeira e do licor branco). Visando maior economia e menor impacto ambiental, esse resíduo é levado a uma unidade de recuperação para geração de vapor, energia elétrica e reaproveitamento dos químicos inorgânicos do processo, reutilizando até $97 \%$ das substâncias químicas utilizadas na polpação (Green e Hough, 1992). Entretanto, muitas indústrias têm gerado uma quantidade de licor negro superior à capacidade de processamento de sua unidade 


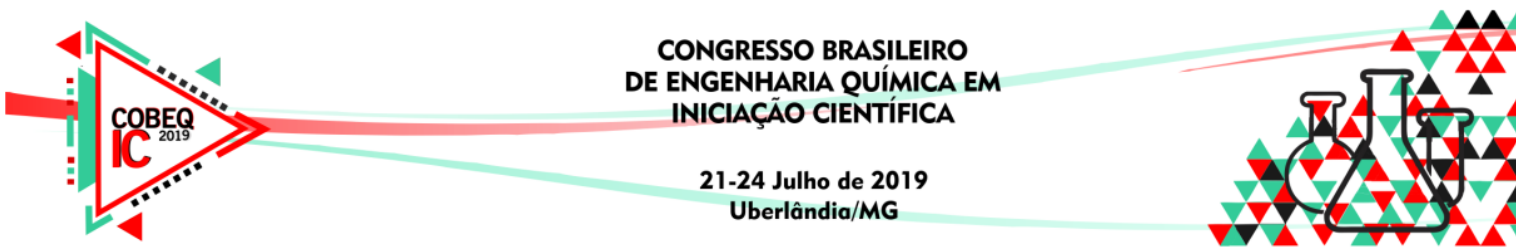

de recuperação. Uma das soluções para mitigar essa situação é recuperar a lignina do licor negro e reutilizá-la para outros fins.

A recuperação da lignina do licor negro já é amplamente estudada no contexto internacional, entretanto não há muitos trabalhos em nível nacional que focam na influência da perda de lignina ou aumento dos sais inorgânicos sobre as propriedades fundamentais do licor. Cardoso et. al., (2008) afirmaram que as características físico-químicas do licor negro são influenciadas, principalmente, pela sua composição química e condição de operação industrial. Como a composição afeta fortemente as propriedades do licor, são apresentados nesse trabalho experimentos laboratoriais que possibilitaram analisar a influência dos principais componentes do licor negro industrial (lignina, $\mathrm{Na}_{2} \mathrm{SO}_{4}$ e $\mathrm{Na}_{2} \mathrm{CO}_{3}$ ) sobre duas das suas características físicas mais importantes: massa específica e teor de sólidos. São propostos modelos de preditivos para ambas propriedades das misturas binárias de lignina e cada um dos sais, determinando o componente que apresenta maior impacto nas propriedades.

\section{MATERIAIS E MÉTODOS}

Primeiramente, foram preparadas em laboratório cinco diferentes concentrações de solução aquosa de lignina. A lignina utilizada foi cedida pela unidade de Limeira (SP) da empresa Suzano Papel e Celulose, consistindo num composto básico e anidro com $85 \%$ de pureza. Em seguida, para cada solução de lignina foi acrescentado $\mathrm{Na}_{2} \mathrm{SO}_{4}$ em quatro diferentes concentrações, totalizando 20 misturas binárias de lignina e $\mathrm{Na}_{2} \mathrm{SO}_{4}$. $\mathrm{O}$ mesmo foi feito com cada uma das cinco concentrações originais de lignina e $\mathrm{Na}_{2} \mathrm{CO}_{3}$ em cinco concentrações, totalizando 25 misturas binárias de lignina e $\mathrm{Na}_{2} \mathrm{CO}_{3}$. Os valores para as concentrações de lignina e de sal em todas as soluções encontram-se resumidos na Figura 1.

Figura 1 - Concentrações para cada mistura binária de lignina com sal.
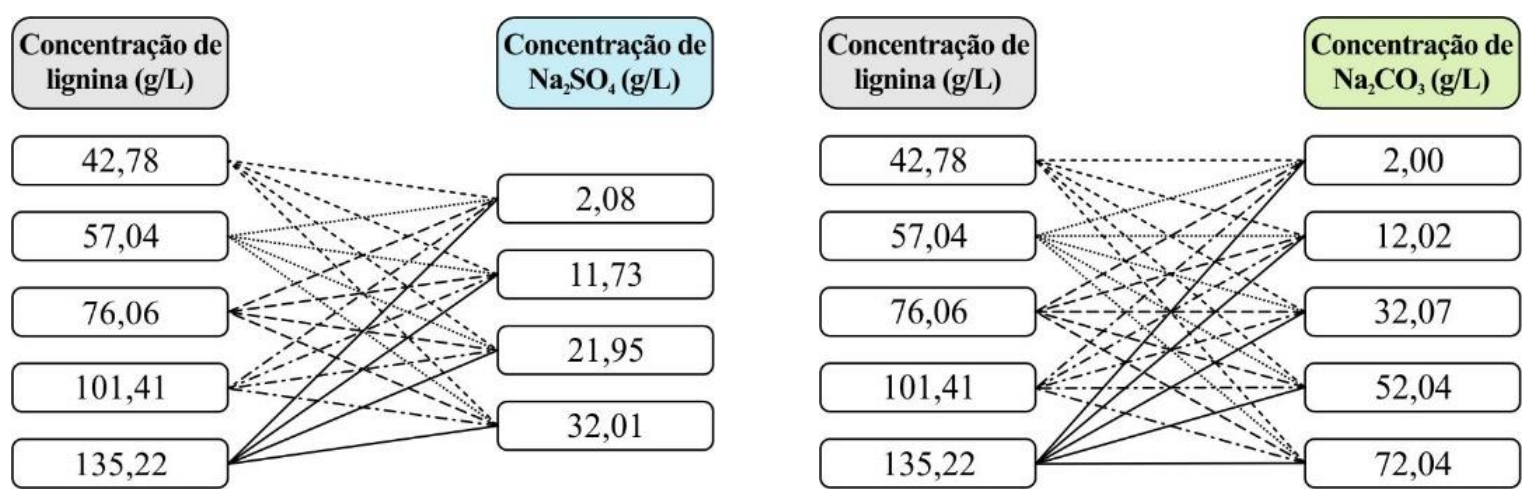

Os valores das concentrações de $\mathrm{Na}_{2} \mathrm{SO}_{4}$ nas soluções em que esse está presente foram escolhidos baseados nas faixas de concentração de sulfato observadas no processo de extração do qual a lignina usada foi obtida. Já as concentrações de $\mathrm{Na}_{2} \mathrm{CO}_{3}$ foram planejadas de acordo com a faixa apresentada por Moosavifar (2008). Em seguida, foram analisadas as massas específicas de cada solução por meio de picnometria à temperatura ambiente. Os picnômetros (50 mL) foram calibrados para determinação de seus volumes reais a partir da Equação 1:

$$
v_{\text {real }}=\frac{m_{\text {cheio }}-m_{\text {vazio }}}{\rho_{\mathrm{H}_{2} \mathrm{O}}}
$$



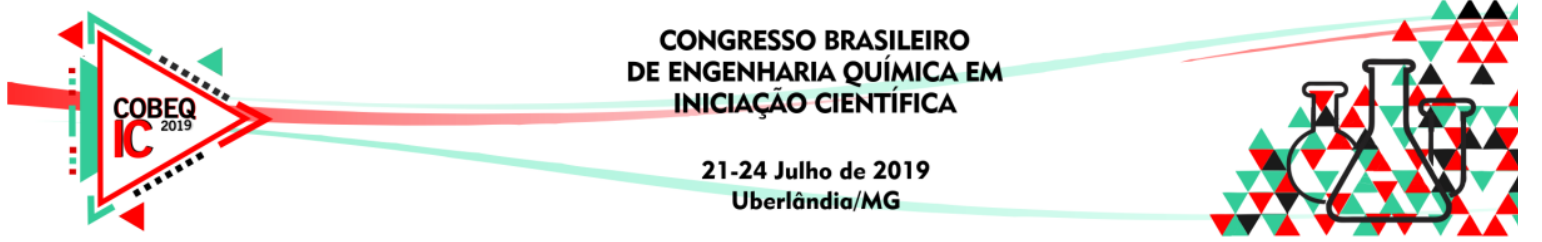

na qual vreal é o volume real do picnômetro $\left(\mathrm{m}^{3}\right)$, m vazio é a massa do picnômetro vazio $(\mathrm{kg})$, $\mathrm{m}_{\text {cheio }}$ é a massa dele preenchido com água destilada $(\mathrm{kg})$ e $\rho_{\mathrm{H} 2 \mathrm{O}}$ é a massa específica da água $\left(\mathrm{kg} / \mathrm{m}^{3}\right)$ na temperatura utilizada $\left(25^{\circ} \mathrm{C}\right)$.

Após a calibração, os picnômetros foram preenchidos com as soluções desejadas e as massas específicas dessas foram calculadas em duplicatas a partir da Equação 2:

$$
\rho_{\text {sol }}=\frac{m_{\text {cheio }}}{v_{\text {real }}}
$$

na qual $\rho_{\text {sol }}$ é a massa específica da solução $\left(\mathrm{kg} / \mathrm{m}^{3}\right), \mathrm{m}_{\text {cheio }}$ é a massa do picnômetro cheio com a solução $(\mathrm{kg})$ e vreal é o volume real do picnômetro $\left(\mathrm{m}^{3}\right)$.

O teor de sólidos foi determinado utilizando-se o método descrito pela norma TAPPI T650 cm-99 "Solids content of Black Liquor. Ele consiste na secagem de uma massa conhecida de solução em Placas de Petri (em duplicata) colocadas em estufa a $105{ }^{\circ} \mathrm{C}$ durante tempo controlado ( 24 horas), até se obter massa constante. O cálculo é apresentado na Equação 3:

$$
\% S T=\frac{m_{\text {úmida }}-m_{\text {vazia }}}{m_{\text {seca }}} * 100
$$

na qual \%ST é a porcentagem de sólidos totais na solução (\%), m vazia é a massa da placa de

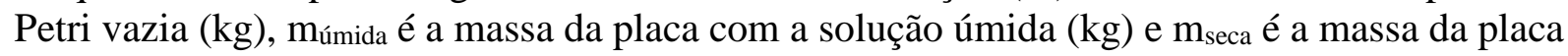
com a solução após a secagem $(\mathrm{kg})$.

\section{RESULTADOS E DISCUSSÃO}

\subsection{Influência dos Sais de Sódio na Massa Específica}

Os valores da massa específica em função da concentração de lignina nas soluções binárias de lignina e $\mathrm{Na}_{2} \mathrm{CO}_{3}$ (a) e de lignina e $\mathrm{Na}_{2} \mathrm{SO}_{4}$ (b) são apresentados na Figura 2.

Figura 2 - Massa específica em função das concentrações de lignina e de sais.
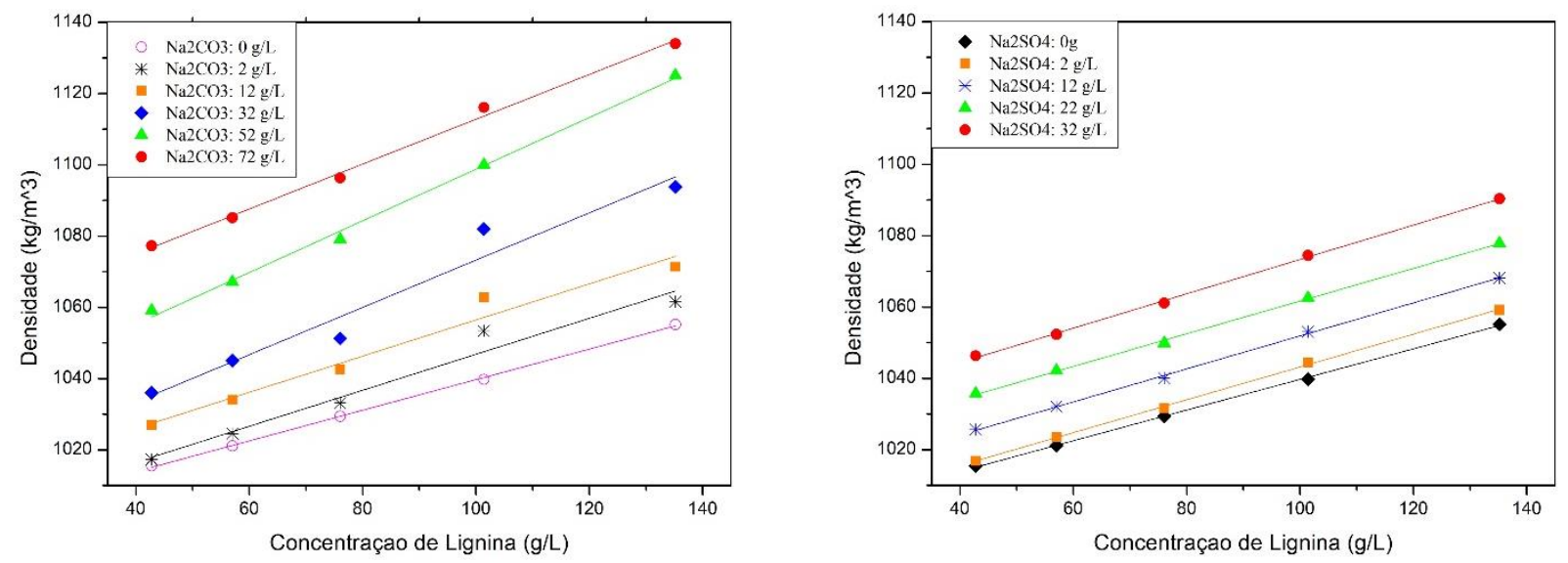


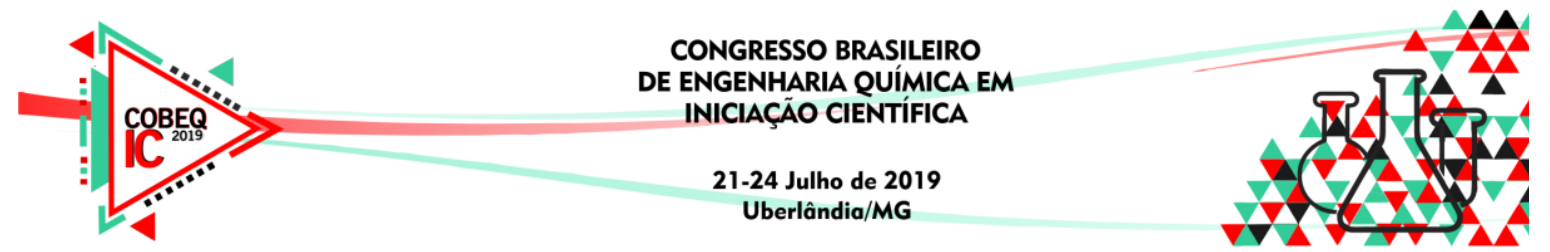

Os valores de $\mathrm{R}^{2}$ dos ajustes lineares das concentrações de sal encontram-se na Tabela 1.

Tabela 1 - Valores de $\mathrm{R}^{2}$ para o ajuste linear da massa específica.

\begin{tabular}{|c|c|c|c|}
\hline \multicolumn{4}{|c|}{ Massa Específica } \\
\hline \hline $\begin{array}{c}\text { Concentração } \\
\text { de } \mathrm{Na}_{2} \mathrm{CO}_{3} \\
(\mathrm{~g} / \mathrm{L})\end{array}$ & $\mathrm{R}^{2}$ & $\begin{array}{c}\text { Concentração de } \\
\mathrm{Na}_{2} \mathrm{SO}_{4}(\mathrm{~g} / \mathrm{L})\end{array}$ & $\mathrm{R}^{2}$ \\
\hline \hline 0 & 0,9992 & 0 & 0,9992 \\
\hline 2 & 0,9566 & 2 & 0,9990 \\
\hline 12 & 0,9591 & 12 & 0,9989 \\
\hline 32 & 0,9430 & 22 & 0,9989 \\
\hline 52 & 0,9954 & 32 & 0,9987 \\
\hline 72 & 0,9940 & - & - \\
\hline
\end{tabular}

Segundo Frederick (1997) e Green e Hough (1992), quando a temperatura é constante e a porcentagem de sólidos é baixa, a massa específica do licor negro é aproximadamente igual à da água. Entretanto, em caso de teores de sólidos mais altos, percebe-se que as massas específicas se distanciam dos valores para a água e passam a variar em função da quantidade de matéria orgânica e inorgânica presentes na solução. Os autores também aponta que os componentes que exercem maior influência nessa propriedade são os inorgânicos, pois, enquanto a massa específica dos orgânicos é próxima à da água, a dos inorgânicos é quase o dobro. A partir dos dados experimentais, desenvolveu-se os modelos para prever a massa específica com base nas concentrações de seus componentes, demosntrando o que exerce maior influência. Vale ressaltar que a massa específica é importante para determinar-se taxas de vazões volumétrica e mássica nos equipamentos industriais e números adimensionais como Reynolds, Peclet e Schmidt necessários em cálculos de design e diagnóstico do processo.

\subsection{Influência dos Sais de Sódio nos Sólidos Totais}

Os valores do teor de sólidos totais em função da concentração de lignina nas soluções binárias de lignina e $\mathrm{Na}_{2} \mathrm{CO}_{3}$ (a) e de lignina e $\mathrm{Na}_{2} \mathrm{SO}_{4}$ (b) são apresentados na Figura 3. Os valores de $\mathrm{R}^{2}$ para os ajustes lineares de cada concentração de sal encontram-se na Tabela 2.

Figura 3 - Sólidos totais em função das concentrações de lignina e de sais.
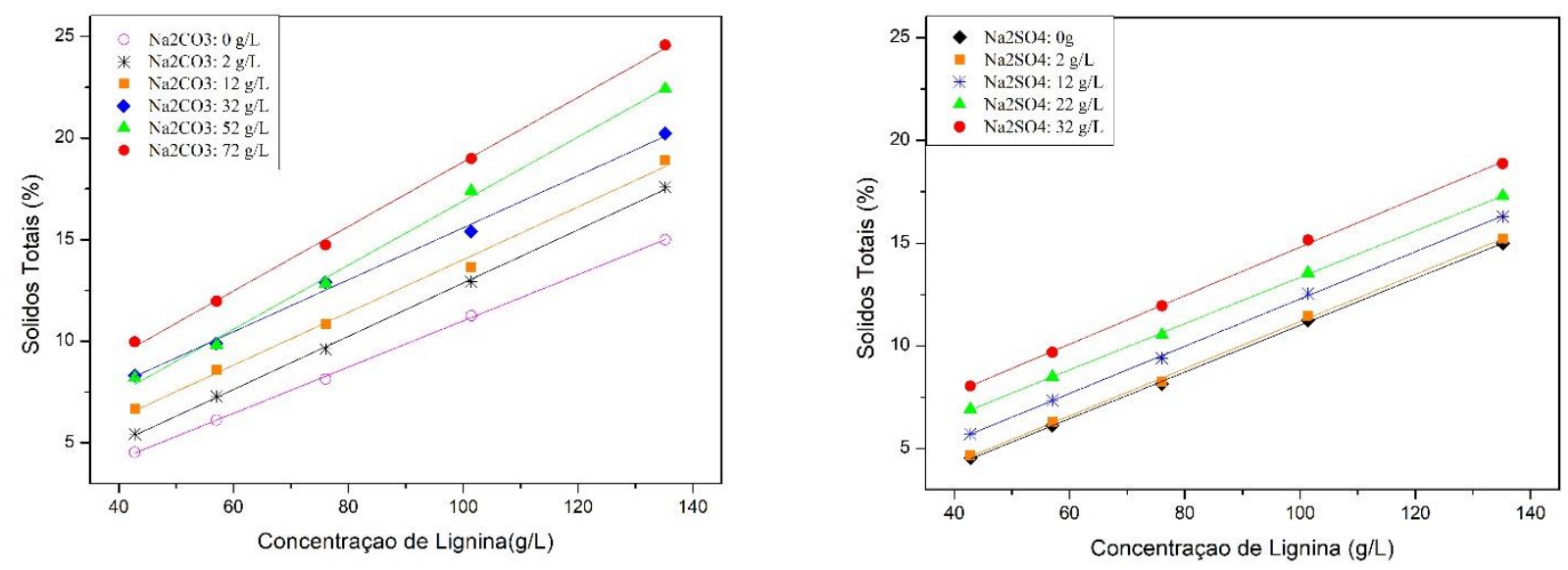


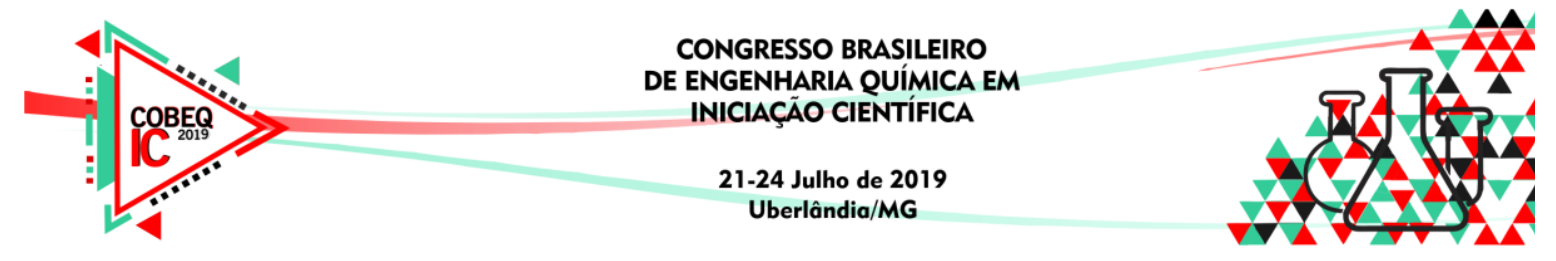

Tabela 2 - Valores de $\mathrm{R}^{2}$ para o ajuste linear dos sólidos totais

\begin{tabular}{|c|c|c|c|}
\hline \multicolumn{4}{|c|}{ Sólidos Totais } \\
\hline \hline $\begin{array}{c}\text { Concentração } \\
\text { de } \mathrm{Na}_{2} \mathrm{CO}_{3} \\
(\mathrm{~g} / \mathrm{L})\end{array}$ & $\mathrm{R}^{2}$ & $\begin{array}{c}\text { Concentração de } \\
\mathrm{Na}_{2} \mathrm{SO}_{4}(\mathrm{~g} / \mathrm{L})\end{array}$ & $\mathrm{R}^{2}$ \\
\hline \hline 0 & 0,9995 & 0 & 0,9995 \\
\hline 2 & 0,9993 & 2 & 0,9993 \\
\hline 12 & 0,9934 & 12 & 0,9994 \\
\hline 32 & 0,9951 & 22 & 0,9997 \\
\hline 52 & 0,9965 & 32 & 0,9992 \\
\hline 72 & 0,9984 & - & - \\
\hline
\end{tabular}

Modelos (apresentados na seção 3.3) para previsão dos sólidos totais de uma solução e análise do impacto de seus componentes nessa propriedade também foram criados com os dados. A análise dos sólidos totais é muito importante na indústria uma vez que eles impactam na viscosidade e o conhecimento desta é essencial ao projetar-se um processo industrial, ao escolher-se e dimensionar-se equipamentos, etc. Segundo Moosavifar (2008), um teor de sólidos alto leva a viscosidade a aumentar e a depender muito tanto dos sólidos totais quanto da temperatura.

\subsection{Correlações}

Por meio do software Minitab $8^{\circledR}$ foram obtidas as correlações entre as propriedades físicas e as concentrações de lignina e cada um dos sais utilizando uma regressão múltipla dos dados. Assim, o software gerou modelos que predizem a massa específica e o teor de sólidos a partir das quantidades de cada componente. $\mathrm{O}$ modelo genérico tem a forma apresentada pela Equação 4, sendo $\mathrm{P}$ a propriedade em questão, $\mathrm{X}_{1}$ a concentração de um dos dois sais e $\mathrm{X}_{2}$ a concentração de lignina. Os coeficientes da equação geral em cada caso são apresentados nas Tabelas 3 e 4 .

$$
P=A+B X_{1}+C X_{2}+D X_{1}^{2}+E X_{2}^{2}+F X_{1} X_{2}
$$

Tabela 3 - Coeficientes dos modelos para as misturas de lignina com $\mathrm{Na}_{2} \mathrm{CO}_{3}$.

\begin{tabular}{|c|c|c|c|c|c|c|}
\hline \multirow{2}{*}{ Propriedade } & \multicolumn{5}{|c|}{ Coeficientes } \\
\cline { 2 - 7 } & $\mathrm{A}$ & $\mathrm{B}$ & $\mathrm{C}$ & $\mathrm{D}$ & $\mathrm{E}$ & $\mathrm{F}$ \\
\hline \hline Massa Específica & 1,00283 & 0,000716 & 0,000347 & 0 & 0,000001 & 0,000003 \\
\hline Sólidos Totais & 0,258 & 0,0878 & 0,10694 & $-0,000632$ & 0,000088 & 0,000496 \\
\hline
\end{tabular}

Tabela 4 - Coeficientes dos modelos para as misturas de lignina com $\mathrm{Na}_{2} \mathrm{SO}_{4}$.

\begin{tabular}{|c|c|c|c|c|c|c|}
\hline \multirow{2}{*}{ Propriedade } & \multicolumn{7}{|c|}{ Coeficientes } \\
\cline { 2 - 7 } & $\mathrm{A}$ & $\mathrm{B}$ & $\mathrm{C}$ & $\mathrm{D}$ & $\mathrm{E}$ & $\mathrm{F}$ \\
\hline \hline Massa Específica & 1,00145 & 0,000736 & 0,000396 & 0,000004 & 0 & 0,000001 \\
\hline Sólidos Totais & $-0,0510$ & 0,10458 & 0,09563 & 0,000055 & 0,000633 & 0 \\
\hline
\end{tabular}




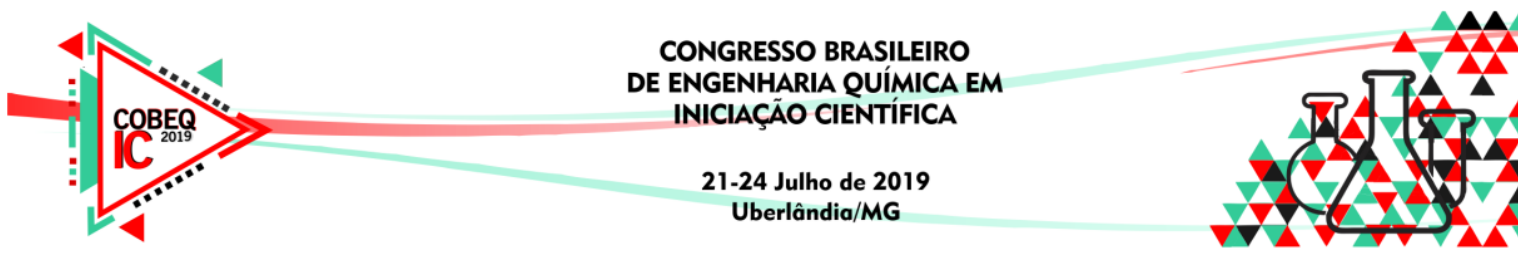

O software também analisa o impacto incremental das variáveis X. Enquanto para a massa específica das misturas contendo $\mathrm{Na}_{2} \mathrm{CO}_{3}$ é o sal que possui maior influência, nas outras soluções o material orgânico apresenta maior impacto na determinação das propriedades físicas. Para a validação do modelo foram preparadas e medidas as massas específicas e sólidos totais de novas soluções de lignina e sulfato de sódio e de lignina e carbonato de sódio. Os valores reais obtidos e preditos, bem como as concentrações das soluções estão presentes na Tabela 5.

Tabela 5 - Validação do modelo preditivo proposto.

\begin{tabular}{|c|c|c|c|c|c|c|c|}
\hline Componentes & Concentração $(\mathrm{g} / \mathrm{L})$ & $\rho_{\text {Exp }}\left(\mathrm{kg} / \mathrm{m}^{3}\right)$ & $\rho_{\text {Prevista }}\left(\mathrm{kg} / \mathrm{m}^{3}\right)$ & Desvio & $\% \mathrm{ST}_{\text {Exp }}$ & $\%$ ST \\
Prevista & Desvio \\
\hline \hline Lignina & 120 & 1050,06 & 1046,3 & $0,4 \%$ & $18,7 \%$ & $19,2 \%$ & $-2,9 \%$ \\
\hline $\mathrm{Na}_{2} \mathrm{CO}_{3}$ & 40 & 1074,33 & 1076,1 & $-0,2 \%$ & $15,1 \%$ & $14,9 \%$ & $1,4 \%$ \\
\hline $\mathrm{Lignina}_{2} \mathrm{SO}_{4}$ & 120 & 15 & $10 \%$ & $14 \%$ \\
\hline
\end{tabular}

Com desvios residuais baixos entre os valores medidos e preditos, é possível dizer que o modelo é funcional para as faixas de concentrações consideradas nesse trabalho e que são de interesse do processo em que se pretende aplicar as mesmas.

\section{CONCLUSÕES}

Segundo Cardoso et. al., (2008) o licor negro possui uma composição química complexa e única que impacta a maioria das operações unitárias do processo de recuperação do método Kraft. Isso se deve à influência que essa composição possui sobre propriedades físicas do licor. A partir dos dados e das análises presentes neste trabalho, pode-se observar que o impacto do material inorgânico (no caso, sais de sódio) sobre a massa específica da solução de cada um deles com lignina, é maior do que o da matéria orgânica. Entretanto, quando se trata do teor de sólidos totais, o inverso é observado. Essas relações são expressas nos modelos apresentados, a partir dos quais é possível estimar essas duas propriedades físicas utilizando apenas as concentrações de lignina e dos sais. Dessa forma, foi possível demonstrar experimentalmente e modelar matematicamente, por meio de análises estatísticas, a importância da relação entre os componentes do licor, visando tornar mais prática a manipulação do mesmo.

\section{REFERÊNCIAS}

CARDOSO, M.; PASSOS, M. L.; OLIVEIRA, E. D. de. Licor negro de eucalipto Kraft proveniente de indústrias brasileiras: características químicas, físicas e seu processamento na unidade de recuperação. O Papel, São Paulo, v. 67, n. 2, p. 57-83, mai. 2008.

GREEN, R.P., HOUGH, G. Chemical recovery in the alkaline pulping process. Alkaline pulping committe of the pulp manufacture, Tappi Press, nº 3, Atlanta, p. 1-24, 1992.

IEA ETSAP. Technology Brief I07. 2015.

A. MOOSAVIFAR, "Lignin Extraction from Black Liquor - Properties of the liquors and sulphur content in the lignin," Chalmers University of Technology, Gothenburg

FREDERICK, W. J., 1997, "Black liquor properties". In: Adams, T. N. e. (Ed.), Kraft recovery boilers, Tappi Press, cap. 3, pp. 61-98, Atlanta, GA, USA. 